\title{
ANÁLISE DE INFORMAÇÕES NUTRICIONAIS EM RAÇÕES PARA GATOS
}

\author{
Antonio Jackson Sousa Lima ${ }^{1}$ \\ Yuri Luiz Boechat ${ }^{2}$ \\ Ligia Mara da Cunha Genovez ${ }^{2}$ \\ Caio Farias $\mathrm{Cabral}^{2}$ \\ Lucas Brenno Rodrigues Silva
}

\begin{abstract}
RESUMO
A alimentação dos animais domésticos se torna cada dia mais exigente e balanceada, visando a melhora na qualidade de vida destes animais. Atualmente, existe uma grande variedade de rações para atender esta demanda e facilitar a oferta de alimentos aos animais pelos tutores. Neste trabalho foram avaliadas as informações nutricionais nos rótulos de rações para felinos domésticos comercializadas na cidade de Bom Jesus- PI e estabelecida a relação preço por quilograma, teor de nutrientes em cada categoria das rações para cada grupo de animais, com o objetivo informativo nutricional e estabelecer uma relação custo-benefício entre as mesmas. Os resultados revelaram que há diferenças entre as rações, seja da mesma classificação, entre elas e/ou grupos diferentes, tanto em questão de preço, como em quantidade e qualidade de nutrientes. Observou-se a mesma ração com preços diferentes, assim como rações da mesma categoria destinada ao mesmo grupo de animais, mas que possuem teores de nutrientes muito distintos. Este estudo ainda levou em conta as rações especiais destinadas a animais com problemas urinários, renais e obesos, demostrando a importância da diferença de nutrientes nas rações para esses animais. Pôde se observar com este trabalho que a escolha da ração baseada na qualidade e quantidade dos nutrientes é imprescindível para fortalecer e nutrir o animal, além de prevenir ou amenizar problemas de saúde, e que o custo com rações não difere muito mediante as categorias apresentadas.
\end{abstract}

Palavras-Chave: alimentação, felinos, nutrientes, categoria

\section{ANALYSIS OF NUTRITIONAL INFORMATION IN CATS FEEDING}

\begin{abstract}
Feeding domestic animals becomes more demanding and balanced every day, aiming to improve the quality of life these animals. Currently, there is a wide variety of feeds to meet this demand and facilitate the supply of food to animals by tutors. In this work, the nutritional information on the food labels for domestic cats sold in the city of Bom Jesus-PI was evaluated and the price per kilogram, nutrient content in each category of feed for each group of animals was established, with the purpose of nutritional information and establish a costbenefit relationship between them. The results show that there is a lot of difference between the rations, whether of the same classification, between them and/or different groups, both in terms of price, and in terms of quantity and quality of nutrients. The same feed with different prices was observed, as well as feed from the same category destined to the same group of animals, but with very different nutrient content. This study also takes into account the special rations for animals with urinary, kidney and obese problems, demonstrating the importance of the difference in nutrients in the rations for those animals. What could be observed with this work is that the choice of feed based on the quality and quantity of nutrients is essential to

\footnotetext{
${ }^{1}$ Universidade Federal do Piauí, Clínica Cirúrgica de Cães e Gatos *Correspondência: jacksonufpi@hotmail.com

${ }^{2}$ Universidade Federal do Piauí, Bacharelando em Medicina Veterinária. ylboechat@outlook.com
} 
strengthen and nourish the animal, in addition to preventing or alleviating health problems, and that the cost of feed does not differ much according to the categories presented.

Keywords: feed, cats, nutrients, category

\section{ANÁLISIS DE INFORMACIÓN NUTRICIONAL EN LA ALIMENTACIÓN DE GATOS}

\section{RESUMEN}

La alimentación de los animales domésticos se vuelve cada día más exigente y equilibrada, con el objetivo de mejorar la calidad de vida de estos animales. Actualmente, existe una amplia variedad de raciones para cubrir esta demanda y facilitar el suministro de alimento a los animales por parte de los tutores. En este trabajo se evaluó la información nutricional en las etiquetas de los alimentos para gatos domésticos vendidos en la ciudad de Bom Jesus-PI y se estableció el precio por kilogramo, contenido de nutrientes en cada categoría de alimento para cada grupo de animales, con el propósito de información nutricional y establecer una relación costo-beneficio entre ellos. Los resultados revelan que existe mucha diferencia entre las raciones, ya sea de la misma clasificación, entre ellas y / o grupos diferentes, tanto en términos de precio, como en términos de cantidad y calidad de nutrientes. Uma misma racion con diferentes precios se observa en las Tablas 1, 2 y 3, así como racion de la misma categoría destinado al mismo grupo de animales, pero con muy diferente contenido de nutrientes. Este estudio también tiene en cuenta las raciones especiales (Tabla 4) para animales con problemas urinarios, renales y obesos, demostrando la importancia de la diferencia de nutrientes en las raciones para estos animales. Lo que se pudo observar con este trabajo es que la elección del alimento en función de la calidad y cantidad de nutrientes es fundamental para fortalecer y nutrir al animal, además de prevenir o aliviar problemas de salud, y que el costo del alimento no difiere mucho según a las categorías presentadas.

Palabras-Clave: alimentación, felinos, nutrientes, categoría

\section{INTRODUÇÃO}

Nos últimos anos é possível notar a grande presença dos animais em ambientes familiares, e ela cresce em volume e em diversidade à medida que aumenta a quantidade de lares no país. Os pets vêm mudando seu status de animais de estimação para membros da família, o que ocasionou em grandes mudanças na alimentação, antes sua principal fonte de alimento, eram os restos das refeições humanas (1), porém hoje é cada vez mais comum a presença de alimentos próprios para esses animais, ocasionando um expressivo desenvolvimento do setor pet food, e isso pode representar o tamanho da importância que esses animais detêm na vida dos humanos e na sociedade (2).

Com isso, também aumentou a busca por alimentos saudáveis que proporcionem uma melhor qualidade de vida, maior aporte energético e valor nutricional para os animais, sendo que de acordo com Associação Brasileira da Indústria de Produtos para Animais de Estimação (3), em 2019 o setor de pet food faturou R \$ 22,3 bilhões só no Brasil. Diante deste cenário é cada vez mais comum o surgimento de produtos para classes específicas de pets, seja por idade (filhote, adulto e sênior), garantindo o suporte nutricional para cada estágio, por raça ou porte (pequeno, médio e grande), ajustando os tamanhos das porções de consumo. Esta segmentação faz com que o nicho de mercado diminua e seja focado para um número mais limitado de consumidores em cada divisão. 
Entretanto, os tutores de animais dificilmente possuem conhecimentos acerca da alimentação adequada a ser oferecida a seus pets e tendem a comprar rações por indicação de marcas ou aquelas que possuem menor valor no Mercado. Este trabalho teve como objetivo fazer um estudo comparativo entre os valores de diferentes categorias de rações, bem como a quantidade de nutrientes expressa nos rótulos, para gatos na cidade de Bom Jesus - PI, avaliando informações relevantes sobre os nutrientes presentes nas rações, que possam ajudar a escolher uma melhor ração de acordo com as necessidades do animal.

\section{MATERIAIS E MÉTODOS}

Foi realizada uma pesquisa de campo em sete casas de rações e comércios que vendem rações para felinos domésticos, na cidade de Bom Jesus, situada ao sul do Estado do Piauí, Brasil.

A pesquisa consistiu em fazer um levantamento de todas as marcas de rações para gatos e seus valores, encontradas no comércio. Durante o levantamento as rações foram separadas por fases de vida e categorias sendo: Fases de vida: Filhotes, Adultos e Castrados; e Categorias: Standard, Premium, Super Premium, Rações especiais.

Após o levantamento, foram realizados cálculos para encontrar a porcentagem de nutrientes em relação ao quilo de ração, com base nos dados fornecidos no verso da embalagem das rações, e também a relação de preço dos nutrientes para cada quilo, fazendo se uso da ferramenta Microsof Excel ${ }^{\circledR}$ de acordo com as informações dos fabricantes, utilizando a seguinte equação para o cálculo de preço de nutriente:

$$
P N=\frac{P k g}{100} * I \% \text {, onde: }
$$

$\mathrm{PN}=$ Preço por nutriente

$\mathrm{Pkg}=$ Preço por quilograma de ração

$\mathrm{I} \%=$ Porcentagem do ingrediente por quilograma

e desta forma analisar o melhor custo-benefício referente em cada produto.

\section{RESULTADOS}

De acordo com a Tabela 1, o preço médio do quilograma de ração para felinos adultos da Categoria premium é de 19,51R \$, sendo a marca Golden como tendo os maiores valores no preço da ração, 32 e $25 \mathrm{R} \$ / \mathrm{Kg}$, em contrapartida a marca Magnus apresentou o menor custo por kg para uma ração premium com preço de mercado cerca de 9,92 R \$, possui ainda $\mathrm{o}$ maior teor de Calcio (Ca) da Categoria com valor de $1,9 \% / \mathrm{kg}$ sendo a média de $1,58 \% / \mathrm{kg}$ e de Matéria Mineral (MM) junto com a marca Maxcat com teores de 10\%/kg sendo a média $8,66 \% / \mathrm{kg}$.

A Proteína Bruta (PB) se destaca como o ingrediente que está em maior quantidade, com média de $31,6 \% / \mathrm{kg}$, destaque para a marca Maxcat que apresenta a maior quantidade de PB das rações da Categoria premium com teor de $34 \% / \mathrm{kg}$, essa ração ainda se distingue por ter teores de nutrientes que se destaca das demais e da média da categoria, como o teor de Umidade (U) acima da média, que foram de $12 \% / \mathrm{kg}$ e $10,33 \% / \mathrm{kg}$ respectivamente, seu baixo teor de Extrato Etéreo (EE) que foi de $9 \% / \mathrm{kg}$ e a média de $10,83 \% / \mathrm{kg}$ e o seu alto teor de Matéria Fibrosa (MF) de 5,5\%/kg sendo a média 3,66\%/kg.

As rações standart para felinos adultos apresentaram maior variedade de mercado com grandes variações de preços entre elas, o preço médio do quilograma é de $12,51 \mathrm{R} \$$, e as marcas Faro e Whiskas se destacaram por terem os maiores valores, mais que o dobro da média da Categoria, sendo 27,5 e $25,5 \mathrm{R} \$ / \mathrm{Kg}$, respectivamente, já a marca Pitukats 
apresentou o menor valor de mercado com preço de 3,5 reais por $\mathrm{kg}$, o que corresponde a quase 4 vezes menos o preço médio da categoria.

Tabela 1. Dados referentes as rações para felinos adultos comercializadas em Bom Jesus-PI.

\begin{tabular}{|c|c|c|c|c|c|c|c|c|c|c|}
\hline \multirow{2}{*}{ Loja } & \multirow{2}{*}{ Marca } & \multirow{2}{*}{ Categoria } & \multirow{2}{*}{$\begin{array}{l}\text { Preço } \\
\mathrm{R} \$ \mathbf{K g} \\
\end{array}$} & \multicolumn{7}{|c|}{ Valores nutricionais/\%/kg } \\
\hline & & & & $\mathbf{U M}$ & PB & $\mathbf{E E}$ & MM & MF & $\mathrm{Ca}$ & $\mathbf{P}$ \\
\hline 1 & Golden & Prem & 25 & 10 & 31 & 12 & 8 & 3,5 & 1,5 & 0,6 \\
\hline 1 & Maxcat & Prem & 22 & 12 & 34 & 9 & 10 & 5,5 & 1,5 & 0,7 \\
\hline 2 & Quartz & Prem & 12 & 10 & & 10 & 7,5 & 3,5 & 1,5 & 0,8 \\
\hline 4 & Sabor e vida & Prem & 16,16 & 10 & 31 & 12 & 8,50 & 3 & 1,6 & 0,7 \\
\hline 4 & Magnus & Prem & 9,92 & 10 & 31 & 10 & 10 & 3 & 1,9 & 0,7 \\
\hline 7 & Golden & Prem & 32 & 10 & 31 & 12 & 8 & 3,5 & 1,5 & 0,6 \\
\hline \multicolumn{3}{|c|}{ Médias } & 19,51 & 10,33 & 31,6 & $\mathbf{1 0 , 8 3}$ & 8,66 & 3,66 & 1,58 & 0,68 \\
\hline 1 & Ultra & Stand & 3,6 & 10 & 27 & 8 & 11 & 4,5 & 1,5 & 0,7 \\
\hline 1 & Mycat & Stand & 7,99 & 12 & 25 & 7 & 11 & 4 & 2 & 0,8 \\
\hline 1 & Kitekat & Stand & 9,49 & 12 & 24 & 8 & 10 & 4 & 2,4 & 0,7 \\
\hline 1 & Ducat & Stand & 9,49 & 9 & 34 & 12 & 8,5 & 3 & 2 & 0,8 \\
\hline 2 & Pitukats & Stand & 9 & 10 & 30 & 10 & 8 & 4 & 1,2 & 0,8 \\
\hline 2 & Mixcats & Stand & 6 & 12 & 30 & 10 & 10 & 4 & 2,4 & 0,7 \\
\hline 2 & Whiskas & Stand & 14,5 & 12 & 30 & 9 & 8,5 & 4 & 1,5 & 0,8 \\
\hline 3 & Golden & Stand & 24 & 10 & 31 & 12 & 8 & 3,5 & 1,5 & 0,6 \\
\hline 3 & Whiskas & Stand & 18,6 & 12 & 30 & 9 & 8,5 & 4 & 1,5 & 0,8 \\
\hline 4 & Whiskas & Stand & 14,3 & 12 & 30 & 9 & 8,5 & 4 & 1,5 & 0,8 \\
\hline 4 & Friskies & Stand & 14 & 12 & 32 & 10 & 8,5 & 3 & 2 & 1 \\
\hline 4 & Pitukats & Stand & 9,8 & 10 & 30 & 10 & 8 & 4 & 1,2 & 0,8 \\
\hline 6 & Street cat & Stand & 9 & 10 & 26 & 9 & 12 & 4,5 & 2,4 & 0,8 \\
\hline 6 & Friskies & Stand & 14 & 12 & 30 & 9 & 8,5 & 4 & 1,5 & 0,8 \\
\hline 6 & Mixcats & Stand & 5 & 12 & 30 & 10 & 10 & 4 & 2,4 & 0,7 \\
\hline 6 & Pitukats & Stand & 3,5 & 10 & 30 & 10 & 8 & 4 & 1,2 & 0,8 \\
\hline 7 & Faro & Stand & 27,5 & 10 & 30 & 11 & 9 & 3 & 1,8 & 0,8 \\
\hline 7 & Whiskas & Stand & 25,5 & 12 & 30 & 9 & 8,5 & 4 & 1,5 & 0,8 \\
\hline \multicolumn{3}{|c|}{ Médias } & 12,5 & 11,05 & 29,38 & 9,55 & 9,13 & 3,86 & 1,75 & $\mathbf{0 , 7 7}$ \\
\hline 4 & Gran plus & Sup-p & 14,14 & 10 & 32 & 13 & 8 & 3 & 1,5 & 0,7 \\
\hline 5 & Sabor e vida & Sup-p & 20 & 10 & 31 & 12 & 8,5 & 3 & 1,6 & 0,7 \\
\hline \multicolumn{3}{|c|}{ Médias } & 17,07 & 10 & 31,5 & 12,5 & 8,25 & 3 & 1,55 & 0,7 \\
\hline
\end{tabular}

Loja1- 2N Distribuidora; Loja2- Agrovida; Loja3- Casa do Vaqueiro; Loja4- Agrocampo; Loja5- Pet\&Gato; Loja6Agrorural; Loja7- Dondocão.

Abrev: Stan - Standard; Prem - Premium; Sup-P - Super Premium.

UM - Umidade; PB - Proteína Bruta; EE - Extrato Etéreo; MM - Matéria Mineral; MF - Matéria Fibrosa; Ca - Cálcio; P Fósforo.

A marca Ducat da Categoria standart destaca-se em três ocasiões, possui o menor teor de UM $(9 \% / \mathrm{kg})$ o maior teor de PB $(34 \% / \mathrm{kg})$ e junto com a marca Golden os maiores teores de EE (12\%/kg), sendo as medias da Categoria para esses nutrientes $11,05 \% / \mathrm{kg}, 29,38 \% / \mathrm{kg}$ e $9,55 \% / \mathrm{kg}$ respectivamente, em contrapartida a marca Kitekat apresenta o menor teor de PB e a Mycat o menor de EE, sendo $24 \% / \mathrm{kg}$ e $7 \% / \mathrm{kg}$ respectivamente. Outros destaques vão para as marcas Street Cat por apresentar o maior teor de MM cerca de $12 \% / \mathrm{kg}$ sendo a média 
9,13\%/kg e para a Friskies com seu teor de Fósforo (P) de $1 \% / \mathrm{kg}$ sendo a média da Categoria de $0,77 \% / \mathrm{kg}$.

Apresentando uma menor quantidade de opções no mercado as rações super premium para felinos adultos, só foram encontradas em dois estabelecimentos comercias dentre os visitados, e apresentaram preço médio de 17,07 R $\$$ por quilograma. Destaque para marca Sabor e vida que apresentou o maior valor de mercado, sendo 20 reais o preço por kg, apesar da diferença de preço, a quantidade de nutrientes dessas rações não tiveram valores divergentes significantes sendo bem semelhantes suas composições.

Levando em consideração os dados da Tabela 1, é observável uma grande variação de preço, as rações da Categoria premium possuem uma média de valor superior as super premium e standart, sendo esta última no geral, a que possui os menores valores de mercado, porém as rações Golden, Whiskas e Faro da Categoria standart apresentaram preços superiores as rações consideradas super premium apresentadas neste estudo. Quanto ao teor de Umidade (U) as rações standart tiveram o maior percentual, seguidos pela premium e super premium, e apesar disto os valores não apresentam diferença significativa. Quanto a comparação da quantidade de nutrientes do grupo, destacam-se as rações Ducat da Categoria standart, por apresentar o menor teor de Umidade do grupo, as rações Maxcat (premium) e Ducat (standart) apresentaram os maiores teores de Proteína Bruta e a Kitekat (standart) apresentou o menor, a Mycat (standart) apresenta o menor teor de Extrato Etéreo e a Gran plus (super premium) o maior, quanto a Matéria Mineral a ração Street Cat (standart) apresentou o maior teor e a Quartz (premium) o menor, já a ração Maxcat (premium) foi destaque por ter o teor mais elevado de Matéria Fibrosa.

De acordo com a Tabela 2, em comparação com as de adultos, as rações para filhotes se mostraram em menor quantidade de variedade nos mercados, sendo em algumas lojas nem mesmo encontradas. O preço médio do quilograma de ração para felinos filhotes da Categoria premium é de 28,83 R\$, destaque para a marca Golden que apresentou duas rações, uma com o maior e a outra com o menor preço, 32 e $25 \mathrm{R} \$$, respectivamente, destaque para a ração com menor valor, a mesma apresentou os maiores teores de PB $(36 \% / \mathrm{kg})$ e MF $(4,5 \% / \mathrm{kg})$ em sua composição, sendo as medias $34 \% / \mathrm{kg}$ e $4,5 \% / \mathrm{kg}$ respectivamente.

O preço médio do quilograma de ração para felinos filhotes da Categoria standart é de 16,22 R\$, destaque para a ração Whiskas que apresentou o maior e o menor valor, diferenciando apenas no local de compra, a Loja 3, foi a que apresentou o maior valor por quilograma (18,6 R\$), e a Loja 2 o menor valor (15 R \$ $/ \mathrm{kg}$ ). Das quatro rações da Categoria standart, três são da mesma marca (Whiskas) e possuem a mesma quantidade de nutrientes, sendo o diferencial a marca Friskies, que apresenta maior teor de PB $(32 \% / \mathrm{kg})$.

Quanto as rações Super Premium para filhotes, só foram encontradas duas marcas em uma mesma loja, sendo o preço médio do quilograma de 34,15 R , com grande destaque para a marca Hill's, que possui um valor 4 vezes maior em comparação com a ração da marca Fino Trato que possui o menor valor da Categoria (55,3 e $13 \mathrm{R} \$$, respectivamente), possuindo também quase o dobro de EE $(21 \% / \mathrm{kg})$ em comparação com a concorrente $(12 \% / \mathrm{kg})$, quanto aos demais ingredientes das rações não houve diferença significativa.

Comparando os destaques da Tabela 2, pode-se observar que as rações Standard possuem um teor médio maior de UM $(12 \% / \mathrm{kg})$ em relação as outras Categorias, já o percentual de PB é maior nas rações Premium (34\%/kg), sendo a Golden da loja 1 que possui o maior teor $(36 \% / \mathrm{kg})$, essa mesma Categoria possui o menor teor de MM sendo a média $8 \% / \mathrm{kg}$. Já a categoria Super Premium destaca-se dentre as três categorias para rações de filhotes, por apresentar a maior média em EE (16,5\%) sendo a ração Hill's a responsável por

Lima AJS, Boechat YL, Genovez LMC, Cabral CF, Silva LBR. Análise de informações nutricionais em rações para gatos. Vet. e Zootec. 2021 dez.; v28: 001-015. 
esse valor apresentando um percentual de $21 \%$ de EE, o qual é maior do que qualquer outra ração para filhotes apresentada na Tabela 2.

Tabela 2. Dados sobre rações para filhotes comercializadas em Bom Jesus-PI.

\begin{tabular}{|c|c|c|c|c|c|c|c|c|c|c|}
\hline \multirow{2}{*}{ Loja } & \multirow{2}{*}{ Marca } & \multirow{2}{*}{ Categoria } & \multirow{2}{*}{$\begin{array}{l}\text { Preço } \\
\text { R\$/Kg }\end{array}$} & \multicolumn{7}{|c|}{ Valores nutricionais/\%/kg } \\
\hline & & & & $\mathbf{U M}$ & PB & $\mathbf{E E}$ & MM & MF & Ca & $\mathbf{P}$ \\
\hline 1 & Golden & Prem & 25 & 10 & 36 & 10 & 7 & 4,5 & 1,3 & 0,8 \\
\hline 7 & Faro & Prem & 29,5 & 10 & 32 & 11 & 9 & 3 & 1,8 & 0,8 \\
\hline 7 & Golden & Prem & 32 & 10 & 34 & 12 & 8 & 3,5 & 1,5 & 0,8 \\
\hline \multicolumn{3}{|c|}{ Médias } & 28,83 & 10 & 34 & 11 & 8 & 3,66 & $\mathbf{1 , 5 3}$ & $\mathbf{0 , 8}$ \\
\hline 2 & Whiskas & Stand & 15 & 12 & 30 & 9 & 8,5 & 4 & 1,4 & 0,7 \\
\hline 3 & Whiskas & Stand & 18,6 & 12 & 30 & 9 & 8,5 & 4 & 1,4 & 0,8 \\
\hline 3 & Friskies & Stand & 16 & 12 & 32 & 10 & 8,5 & 3 & 1,6 & 1 \\
\hline 4 & Whiskas & Stand & 15,3 & 12 & 30 & 9 & 8,5 & 4 & 1,4 & 0,7 \\
\hline \multicolumn{3}{|c|}{ Médias } & 16,2 & 12 & 30,5 & 9,25 & 8,5 & 3,75 & 1,45 & 0,8 \\
\hline 4 & Fino trato & Sup-p & 13 & 9 & 30 & 12 & 8,5 & 3 & 1,5 & 0,8 \\
\hline 4 & Hill's & Sup-p & 55,3 & 8 & 31 & 21 & 9 & 4 & 1,7 & 0,7 \\
\hline \multicolumn{3}{|c|}{ Médias } & 34,15 & 8,5 & 30,5 & 16,5 & 8,75 & 3,5 & 1,6 & 0,75 \\
\hline
\end{tabular}

Loja1- 2N Distribuidora; Loja2- Agrovida; Loja3- Casa do Vaqueiro; Loja4- Agrocampo; Loja5-Pet\&Gato; Loja6- Agrorural; Loja7- Dondocão.

Abrev: Stan - Standard; Prem - Premium; Sup-P - Super Premium.

UM - Umidade; PB - Proteína Bruta; EE - Extrato Etéreo; MM - Matéria Mineral; MF - Matéria Fibrosa; Ca - Cálcio; P Fósforo.

Como pode ser observado na Tabela 3, em todas as lojas que se realizou a pesquisa, não foram encontradas rações Standard para felinos castrados, o preço médio do quilograma de ração da Categoria premium é de $22,13 \mathrm{R} \$ / \mathrm{kg}$, destacando a marca Golden da Loja 7 como a que possui maior custo, sendo o valor de 33 reais por quilograma, em contrapartida a marca Quartz apresentou o menor custo por quilo de ração $(12 \mathrm{R} \$ / \mathrm{kg})$. Foram encontradas rações da marca Golden em outras duas lojas $\left(\begin{array}{lll}1 & \text { e } & 3\end{array}\right)$ e as mesmas apresentaram percentuais de nutrientes iguais as da loja 7, porém com custo bem menor, essas rações apresentaram teor de $36 \%$ de $\mathrm{PB}$, sendo destaque também na MM tendo menores teores $(7 \% / \mathrm{kg})$ e por ter o maior percentual de MF (4,5\%/kg) dentre a categoria premium, as marcas Quartz e Magnus apresentaram os menores teores de PB $(31 \% / \mathrm{kg})$, a Magnus ainda se destaca por ter o maior teor de MM da Categoria $(10 \% / \mathrm{kg})$ de $\mathrm{Ca}(1,9 \% / \mathrm{kg})$ e o menor de $\mathrm{MF}(3 \% / \mathrm{kg})$.

$\mathrm{Na}$ categoria Super Premium só foram encontrados dois tipos de ração em uma mesma loja, há uma pequena diferença no preço das mesmas, destaque para Gran Plus que apresenta o maior valor comercial por quilograma (22 R\$) do que a marca Sabor e Vida (20 R\$/kg), possuindo também um maior percentual de $\mathrm{PB}$, cerca de $36 \% / \mathrm{kg}$ contra $32 \% / \mathrm{kg}$ da concorrente, no restante, sem mais diferenças significantes.

$\mathrm{Na}$ comparação de preços entre as médias das duas Categoriais não houve uma diferença significativa, porém no individual a Categoria premium possui o maior e o menor valor de mercado por quilograma de ração para gatos castrados. Quanto aos nutrientes, a ração Golden (premium, loja 1, 3 e 5) e a Gran plus (super premium) possuem o mesmo percentual de $\mathrm{PB}$ por quilograma (36\%), quanto ao EE e MM as rações premium possuem um teor superior, principalmente a Quartz e a Magnus, respectivamente, já a Sabor e Vida (super premium) possui teor superior de MF do que as rações premium.

$\mathrm{Na}$ Tabela 4 estão descritos os dados das rações especiais, os mesmos diferem entre si, pois são para felinos com condições especiais diferentes, e a Premier foi a única marca encontrada nesta pesquisa, que é destinada a esses animais. Das quais a especial 3 descrita 
nesta tabela, é destinada a felinos com problemas de obesidade, possui um percentual bem maior que as demais de PB (42\%/kg), MM (8,5\%/kg), MF $(15 \% / \mathrm{kg}), \mathrm{Ca}(1,3 \% / \mathrm{kg})$ e $\mathrm{P}(0,6 \% / \mathrm{kg})$, porém seu percentual de EE é duas vezes menor que as outras rações especiais (10 e $20 \% / \mathrm{kg}$ respectivamente). Já as rações especiais para felinos com problemas renais e urinário, são semelhantes em sua composição, diversificando principalmente no teor de $\mathrm{Ca}$, onde a Premier Especial 2 (urinário) possui um percentual maior do que a Especial $1(0,9$ e $0,6 \%$ ) respectivamente.

Tabela 3. Dados sobre rações para felinos castrados comercializadas em Bom Jesus-PI.

\begin{tabular}{|c|c|c|c|c|c|c|c|c|c|c|}
\hline \multirow{2}{*}{ Loja } & \multirow{2}{*}{ Marca } & \multirow{2}{*}{ Categoria } & \multirow{2}{*}{$\begin{array}{l}\text { Preço } \\
\text { R\$/Kg }\end{array}$} & \multicolumn{7}{|c|}{ Valores nutricionais/\%/kg } \\
\hline & & & & UM & PB & $\mathbf{E E}$ & MM & MF & Ca & $\mathbf{P}$ \\
\hline 1 & Golden & Prem & 25 & 10 & 36 & 10 & 7 & 4,5 & 1,3 & 0,8 \\
\hline 2 & Quartz & Prem & 12 & 10 & 31 & 11 & 8 & 4 & 1,6 & 0,8 \\
\hline 3 & Golden & Prem & 27 & 10 & 36 & 10 & 7 & 4,5 & 1,3 & 0,8 \\
\hline 4 & Magnus & Prem & 13,66 & 10 & 31 & 10 & 10 & 3 & 1,9 & 0,7 \\
\hline 7 & Golden & Prem & 33 & 10 & 36 & 10 & 7 & 4,5 & 1,3 & 0,8 \\
\hline \multicolumn{3}{|c|}{ Médias } & 22,13 & 10 & 34 & 10,2 & 7,8 & 4,1 & 1,48 & 0,78 \\
\hline 5 & Gran plus & Sup-p & 22 & 10 & 36 & 9 & 8,2 & 4 & 1,7 & 0,7 \\
\hline 5 & Sabor e vida & Sup-p & 20 & 10 & 32 & 9 & 8,5 & 5 & 1,6 & 0,7 \\
\hline \multicolumn{3}{|c|}{ Médias } & 21 & 10 & 34 & 9 & 8,35 & 4,5 & 1,65 & 0,7 \\
\hline
\end{tabular}

Loja1- 2N Distribuidora; Loja2- Agrovida; Loja3- Casa do Vaqueiro; Loja4- Agrocampo; Loja5- Pet\&Gato; Loja6Agrorural; Loja7- Dondocão.

Abrev: Stan - Standard; Prem - Premium; Sup-P - Super Premium.

UM - Umidade; PB - Proteína Bruta; EE - Extrato Etéreo; MM - Matéria Mineral; MF - Matéria Fibrosa; Ca - Cálcio; P Fósforo.

Tabela 4. Rações para animais em condições especiais comercializadas em Bom Jesus-PI.

\begin{tabular}{|l|c|c|c|l|l|l|l|l|l|}
\hline \multirow{2}{*}{ Marca } & \multirow{2}{*}{ Categoria } & \multirow{2}{*}{$\begin{array}{c}\text { Preço } \\
\text { R\$/Kg }\end{array}$} & \multicolumn{6}{|c|}{ Valores nutricionais/\%/kg } \\
\cline { 5 - 10 } & & UM & PB & EE & MM & MF & Ca & P \\
\hline Premier & Espec 1 & 64 & 10 & 24 & 20 & 6 & 3,5 & 0,6 & 0,3 \\
\hline Premier & Espec 2 & 74 & 10 & 25 & 20 & 6 & 3,5 & 0,9 & 0,4 \\
\hline Premier & Espec 3 & 63,3 & 10 & 42 & 10 & 8,5 & 15 & 1,3 & 0,6 \\
\hline \multicolumn{2}{|l}{ Médias } & $\mathbf{6 7 , 1}$ & $\mathbf{1 0}$ & $\mathbf{3 0 , 3 3}$ & $\mathbf{1 6 , 6 6}$ & $\mathbf{6 , 8 3}$ & $\mathbf{7 , 3 3}$ & $\mathbf{0 , 9 3}$ & $\mathbf{0 , 4 3}$ \\
\hline
\end{tabular}

Especial - Para felinos com problemas renais, urinários e de obesidade, respectivamente.

UM - Umidade; PB - Proteína Bruta; EE - Extrato Etéreo; MM - Matéria Mineral; MF - Matéria Fibrosa; Ca - Cálcio; P Fósforo.

\section{DISCUSSÃO}

A diferença básica entre as categorias de ração standard, premium e super premium é a composição da matéria prima (vegetal e/ou animal) e o nível de nutrientes (4) assim como absorção de proteínas que cada uma promove, o que vai influenciar diretamente no preço do produto. Porem a discordância com essa última afirmação, pois como demonstrado por esse estudo, há rações da Categoria standart com preço de mercado superior as rações consideradas super premium (Tabela 1). Para um pensamento mais lógico, rações da Categoria super premium são tidas como as mais caras do mercado, seguidas pelas premium, sendo as standart mais acessíveis, que são conhecidas pelo seu baixo custo-benefício, isso deve-se pela sua formulação, pois são feitas com ingredientes de menores custos e quantidades de proteínas de origem animal e vegetal, já as rações da linha Premium possuem ingredientes de alta absorção e aproveitamento pelo animal, o que as torna de um valor de mercado um pouco maior, por último a super premium, que é o produto de melhor qualidade, possui uma composição ideal 
para os animais, com ingredientes selecionados e tecnologias inovadoras que proporcionam uma melhor absorção que as demais (5), neste estudo também foi possível observar que a mesma ração em lojas diferentes apresentaram preços por quilograma diferentes (Tabela 1, 2 e 3), a explicação mais lógica para essas duas questões é de que tanto a marca como a loja podem agregar valor ao produto (6), quando as mesmas são tidas como melhores do que as outras.

Os valores de todos os níveis de nutrientes preconizados aqui apresentados são da Instrução Normativa $n^{\circ}$ 9, de 2003 (7). regulamentados pela MAPA (8).

Uma ração bem formulada é importante para a nutrição do animal, como também manter a qualidade do produto, como no caso da umidade (9), o tempo de conservação do produto, assim como a probabilidade de proliferação de micro-organismos patogênicos são afetadas diretamente pelo nível de umidade, o MAPA (8) estabelece que rações para gatos adultos tenham um nível de $12 \%$ no máximo e, as médias declaradas no presente estudo são de $11,05 \%$ para rações standart, $10,33 \%$ para as premium e $10 \%$ para as super premium, em estudo aprofundado Souza et al. (10) observaram valores diferentes entre os declarados (VD) e valores observados (VO), onde os valores declarados nos rótulos eram inferiores aos observados, porém todos dentro do limite exigido pela legislação. Em comparação com seus resultados é observada semelhança, onde as rações standart apresentam os maiores níveis de umidade e as rações super premium os menores.

É fato que em todas as tabelas o elemento que mais se destaca na quantidade é a PB, estas cadeias de aminoácidos são os nutrientes mais importantes de uma ração por serem necessárias para diversas funções no organismo. Para gatos adultos de acordo com o MAPA (8) a porcentagem mínima que uma ração deve ter para ser considerada ideal é de $24 \%$, e a média do teor de PB das três Categorias apresentadas neste trabalho estão acima do teor recomendado, sendo elas $29,38 \%$ para a standart, $31,6 \%$ para premium e $31,5 \%$ para a super premium. Souza et al. (10) encontraram valores médios de $28 \%, 29 \%$ e $30 \%$ para rações standart, premium e super premium, respectivamente, para gatos adultos.

Quanto ao extrato etéreo, que é basicamente a quantidade de gordura presente na ração, os valores médios observados foram de $9,55 \%$ para as rações standart, $10,83 \%$ para as premium e $12,5 \%$ para as rações super premium. O MAPA (8) preconiza um valor mínimo de $8 \%$, o que coloca todas as categorias como regulares, com exceção da ração Mycat da categoria standart da loja 1, que apresentou teor de 7\% de EE. No estudo de Souza et al. (10) tanto os valores observados como os declarados estavam dentro das exigências necessárias, porém uma observação feita é que nas três categorias os valores observados eram maiores que os declarados $(\mathrm{VO}=12 \%, 11 \%$ e $10 \%, \mathrm{VD}=9 \%, 9,7 \%$ e $9 \%$, para rações standart, premium e super premium, respectivamente), o que alerta, pois a quantidade que está no rotulo pode não ser a mesma presente na ração, podendo se fornecer mais que o necessário para o animal.

A Matéria Mineral refere-se ao total de minerais que estão presentes na composição do alimento, esses compostos inorgânicos compõem os dentes e ossos do animal. Além disso, os minerais ajudam nos músculos, células sanguíneas e sistema nervoso, os valores médios apresentados por este estudo são de $9,13 \%$ para as rações standart, 8,66\% para as premium e $8,25 \%$ para as super premium, de acordo com a Instrução Normativa $n^{\circ} 9$ de 2003 (7) e o teor de MM para gatos adultos não deve exceder $12 \%$, levando isso em conta, todas as médias estão dentro do padrão estabelecido. Os valores declarados aqui divergem com as afirmações de Carciofi et al. (11) que relatam que as rações standart contém uma quantidade inferior de MM, por ter uma porcentagem superior de ingredientes de origem vegetal em sua formulação, e que as rações premium e super premium contém uma quantidade acima devido na sua formulação serem utilizadas uma quantidade maior de farinha de osso e carne.

Matéria fibrosa é a parte que não é digerida pelos felinos, principal responsável pela formação do bolo fecal, e de acordo com o MAPA (8) rações para felinos adultos devem 
conter no máximo 5\% de MF. No presente estudo as rações standart, premium e super premium para felinos adultos apresentaram médias de 3,86\%, 3,66\% e 3\% respectivamente. Um destaque nesta pesquisa vai para a ração da marca Maxcat da categoria premium na loja 1 que apresentou teor acima do recomendado, com uma porcentagem de 5,5\%. Valores acima de $5 \%$ de fibra bruta influência na digestibilidade de diversos nutrientes, o que ocasiona uma demanda maior de ração e consequentemente maior produção fecal (12).

Esse excesso de fibra pode ocasionar aumento na fermentação microbiana (13), ocasionando dilatação do lúmen intestinal, dor, desconforto, aumento de osmolaridade, diminuição na absorção de nutrientes e até diarreias (14). De acordo com Carciofi et al. (15) esse aumento ocorre devido a inclusão de farelos e alimentos de origem vegetal para diminuir custos com a produção. Segundo Earle et al. (16) essa prática pode comprometer a digestão e absorção de alimento, o que pode afetar a vida do animal. Afonso et al. (17) afirmam que isso ocorre em maior frequência em rações de menor valor de mercado, no entanto a ração em questão é considerada premium e possui um valor de mercado acima da média da categoria.

Quanto aos teores de cálcio e fosforo das rações para gatos adultos a Instrução Normativa $n^{\circ} 9$, de 2003 (7), estabelece o máximo de 2,4\% de Ca e mínimo de $0,6 \%$ de $\mathrm{P}$, esses compostos dentre outras funções são a principal composição dos ossos, comparando com as médias dos valores obtidos de rações para gatos adultos (Tabela 1) observa-se que as rações standart possuem teores maiores desses nutrientes descritos nos rótulos, porém dentro dos padrões estabelecidos. De acordo com Carciofi et al. (18) esse aumento é devido aos coprodutos utilizados como farinha de ossos, farinha de penas, dentre outros, o que contribui para o aumento nos teores de matéria mineral na ração, principalmente cálcio e fósforo.

Quanto as rações para filhotes (Tabela 2) apresentou preço médio de mercado superior a todos os outros grupos, com exceção apenas para as rações especiais (Tabela 4) isso deve-se que a ração voltada para filhote é mais cara pois estes estão em fase de desenvolvimento e demandam maior nível de energia e nutrientes de boa qualidade, e de acordo com Carciofi (11) é o período em que acontece o desenvolvimento de todos os tecidos e órgãos. De acordo com a instrução normativa $n^{\circ} 9$ de 2003 (7), o teor de umidade em rações secas para filhotes não deve ultrapassar $12 \%$ e todos os valores declarados nos rótulos estão de acordo com o padrão estabelecido, a textura macia de rações por conta do maior teor de Umidade é ideal para filhotes.

De acordo com a regulamentação do MAPA (8) o teor mínimo de proteína bruta para rações de gatos filhotes é de $24 \%$, levando em consideração os rótulos das rações e as médias das categorias, pode se observar que todas estão dentro dos padrões estabelecidos, destaque para a ração premium da marca Golden que apresentou o maior percentual do nutriente. Segundo Seixas et al. (19) este grupo de felinos necessitam de mais alimentos ricos em proteína devido a formação de novos tecidos associado a fase de crescimento, e esta deve ser de alta qualidade e de fácil digestão, para garantir a liberação de todos os aminoácidos essenciais para o crescimento e desenvolvimento.

O extrato etéreo assim como os carboidratos, possuem também como função fornecer energia para todas as atividades metabólicas dos organismos, o teor mínimo determinado pelo MAPA (8) para rações de filhotes é de $8 \%$, e todas as categorias estão dentro do padrão estabelecido, apesar de mínimo todas as médias do grupo de ração para filhotes estão acima das médias dos demais grupos, isso deve-se principalmente pelo fato de filhotes requererem um pouco mais de gorduras pelo seu grande gasto de energia, devido ao desenvolvimento e pela característica do filhote de ser bastante ativo.

Quanto a matéria fibrosa o MAPA (8) determina que o percentual não deve ultrapassar $4,5 \%$ na ração para filhotes, todas as rações estavam dentro do valor permitido. Fibras são importantes, porém deve-se ficar atento, em excesso, impede a boa digestão podendo causar desnutrição, já em escassez dificulta o trânsito intestinal o que pode causar constipação. 
Panasevich et al. (20) ressaltam a importância da mesma para manutenção do trato gastrointestinal, por estimularem os enterócitos, colonócitos, peristaltismos, produção de ácidos graxos, diminuindo os riscos de constipação e fecalomas.

É estabelecido pelo MAPA (8) que o teor máximo de matéria mineral para filhotes é de $12 \%$, nenhuma ração do grupo ultrapassou o limite. Quanto ao Cálcio é determinado que o percentual máximo não deve ultrapassar $2 \%$, já o Fósforo o teor mínimo é de $0,8 \%$, nenhuma média ou ração apresentada na tabela 2 ultrapassou o limite de Ca, porém o de $\mathrm{P}$, três rações não atingiram o limite mínimo estabelecido. Em estudo WORTINGER (21) afirma que as rações comercializadas contêm níveis desses dois elementos acima do recomendado, o que contradiz o que está nos rótulos das rações pesquisadas neste trabalho. Association of America Feed Control Official (22) diz que na fase de crescimento a quantidade de cálcio e fósforo exigido pelo organismo é de $1 \%$ para cálcio e $0,8 \%$ para fósforo. Vellasco et al. (23) afirmam que esses minerais estão envolvidos em vários processos metabólicos, com destaque na formação óssea, na excitabilidade, na transmissão neural, na coagulação sanguínea e na estabilização das membranas celulares. Nelson e Couto (24) relatam que a deficiência de fosforo em cães e gatos afetam os sistemas hematológico e neuromuscular, sendo a anemia a sequela mais comum, sendo que os sinais neuromusculares incluem fraqueza, ataxia e convulsões, assim como anorexia e vômitos secundários a obstrução intestinal. Oliveira (25) complementa afirmando que a deficiência de fósforo causa raquitismo e redução do crescimento em animais jovens.

Na Tabela 3 está expressa os dados referentes aos nutrientes informados nos rótulos das rações para gatos castrados, todos os valores estão de acordo com a Instrução Normativa $n^{\circ} 9$, de 2003 (7). As médias do teor de proteína bruta dessas rações estão entre as mais altas deste trabalho, acreditava-se que teria que reduzir a quantidade de PB assim como de extrato etéreo para evitar obesidade nesses animais, porém segundo Wortinger (21) em comparação com gatos inteiros, os castrados não diminuem suas atividades, sua exigência nutricional é reduzida em cerca de 24 a $33 \%$ devido a taxa metabólica basal, e a PB continua sendo muito importante para o organismo, pois servem como enzimas, hormônios, anticorpos, fonte de energia, entre outras funções (26), Segundo Rogers e Morris (27), o gato adulto necessita de 12 a $15 \%$ de proteína oriunda da dieta apenas para sua manutenção.

O teor de matéria fibrosa para gatos castrados (Tabela 3) está próximo do limite máximo regulamentado pelo MAPA (8) para a gatos adultos (5\%), de acordo com o NRC (28) a fibra nos alimentos favorece, além da redução na densidade energética, o controle da glicemia e lipidemia, retarda a absorção dos nutrientes, aumenta saciedade e favorece o menor consumo de alimentos. Essas rações foram formuladas para evitar o ganho de peso excessivo desses animais, porém deve-se tomar cuidado com o excesso de fibra, que pode trazer problemas intestinais e má nutrição ao animal.

$\mathrm{Na}$ Tabela 4 estão apresentados os dados sobre os nutrientes que compõem as rações especiais declarados pelo fabricante, são rações que possuem o maior custo por quilograma devido a sua composição e finalidade (animais em condições especiais), entre a ração especial 1 e 2, não há diferença significativa em relação ao teor dos nutrientes. A porcentagem de Proteína Bruta nessas rações foi de 24 e $25 \%$ respectivamente. De acordo com Reis (29) se supõe que a quantidade mínima para gatos com doença renal crônica assemelha-se com a necessidade de gatos normais, que no caso é de $24 \%$ conforme o MAPA (8), portanto estavam bem perto do limite estabelecido. Isso deve-se principalmente por conta do nível de ureia no sangue, já que a mesma varia muito com a ingestão de proteína na alimentação, o que para animais com problemas renais pode ser prejudicial em níveis mais altos, em contrapartida não pode ter um teor muito baixo para não ocorrer desnutrição do animal.

As Rações especiais 1 e 2 (Tabela 4) ainda possuem teor elevado de extrato estéreo em relação as outras rações, cerca de $20 \%$ cada, o MAPA (8) preconiza um teor mínimo de $8 \%$.

Lima AJS, Boechat YL, Genovez LMC, Cabral CF, Silva LBR. Análise de informações nutricionais em rações para gatos. Vet. e Zootec. 2021 dez.; v28: 001-015. 
De acordo com Reis (29) é recomendado que dietas terapêuticas possuam em sua composição alta densidade energética, para reduzir a quantidade de alimento necessária para suprir exigência nutricional do animal, ocorrendo uma menor distensão gástrica evitando náuseas e vomitos, comuns em crises urêmicas.

Em comparação com todas as outras rações avaliadas, fica nítido um menor teor de Fósforo e principalmente de Calcio nas rações especiais 1 e 2 (Tabela 4), isso deve-se as mesmas serem para animais com problemas semelhantes (renal e urinário). De acordo com Birchard e Sherding (30) uma a alimentação sem restrição moderada de determinados minerais pode ser um fator contribuinte para progressão da doença. Sendo o cálcio em alta quantidade, o principal mineral em ocasionar ou agravar problemas em todo o sistema urinário. De acordo com a Instrução Normativa no 9, de 2003 (7) o nível máximo de Ca deve ser de $2,4 \%$, quanto ao $\mathrm{P}$ o mínimo é de $0,6 \%$, o mesmo não foi atingido, mas é aceitável em virtude da condição a quem é destinada este tipo de ração, pois esses animais tendem a reter íon de fósforo ocasionando hiperfosfatemia sistêmica, o que reduz o cálcio extracelular, afetando a produção de vitamina D que pode ocasionar hipocalemia (29).

Quanto a ração especial 3 (Tabela 4) é destinada para gatos obesos, esses animais requerem uma ração própria para oferecer uma qualidade de vida e nutricional melhor. $\mathrm{O}$ alto teor de proteína bruta visa a manutenção da massa magra (músculos) e dar aporte energético necessário para os processos metabólicos durante o processo de emagrecimento (31). O teor de PB apresentado pela ração especial 3 foi maior que qualquer outra ração deste trabalho. Case et al. (32) demonstraram que gatos que receberam dietas contendo 46\% de proteína mostraram maior perda de gordura e de manutenção de massa magra em comparação a gatos que receberam alimentos com 36\% de proteína na dieta. De acordo com Mendes et al. (33) durante a digestão de dietas ricas em proteínas há um gasto energético maior para a realização do processo.

O teor de extrato etéreo da ração especial 3 é o menor dos apresentados na tabela 4, mas isso deve-se, a fato da mesma ser destinada a animais obesos, com o intuito de auxiliar na redução de peso. As gorduras presentes nas rações possuem maior densidade calórica e são facilmente armazenadas em forma de gordura corporal como reserva energética além de aumentarem a palatabilidade da dieta, são fontes de ácidos graxos essenciais que são importantes para homeostase do organismo na renovação de células, para o sistema imune, na função reprodutiva, dentre outras (31). O percentual apesar de ser o mais baixo da Tabela 4 está bem próximo das demais rações. De acordo com Case et al. (32) em dietas com o objetivo de reduzir o peso o teor de gordura deve ter entre 6 a $11 \%$ na matéria seca, o que está de acordo com a presente ração.

Quanto ao teor de matéria fibrosa, a ração especial 3 (Tabela 4) apresenta o maior teor da categoria e de todas as rações apresentadas neste trabalho o que é ideal para animais obesos a quem é destinada, no geral as fibras nas dietas afetam na digestibilidade dos alimentos, reduzem a absorção de glicose presente nos carboidratos (hiperglicemia), reduzem a gordura do sangue (lipidemia), devido a um menor aproveitamento dos alimentos aumenta a quantidade de massa fecal (32) além de melhorar o trânsito intestinal e por não ser totalmente digerida aumenta o tempo de saciedade do animal. De acordo com Farcas et al. (34) rações com alto teor de fibra são utilizadas para alimentação de animais obesos e diabéticos, para estimular a perda de peso e melhorar o índice glicêmico.

Em resumo, apesar de valores médios bem semelhantes, é muito importante o conhecimento sobre qual ração fornecer ao animal, pois a Categoria dessa, serve para mostrar quais são feitas com matéria prima e nutrientes de qualidade. Houve grandes diferenças de nutrientes, porém os níveis mais altos pode não apresentar maior quantidade de aminoácidos essenciais (35) a consequência disso é um desempenho inferior do animal (36), além do mais 
uma nutrição inadequada pode acarretar prejuízos a saúde. Fornecer alimentos de qualidade é previnir gastos futuros com médico e medicações para o seu animal.

Ressalta-se que as rações a granel não foram utilizadas neste estudo por não apresentarem o rotulo do produto, o que dificulta saber a proporção de nutrientes que a mesma possui, sendo que as mesmas também podem sofrer alterações na sua composição, por ficarem expostas ao ambiente. Já as rações especiais por serem específicas e destinadas a animais com problemas de saúde não devem ser comparadas com as rações para gatos sadios, e as mesmas foram apresentadas neste estudo para fins de conhecimento.

\section{CONCLUSÃO}

$\mathrm{Na}$ escolha de uma boa ração deve-se considerar antes de tudo a saúde do seu animal, como também a idade, o porte e atividade física. De acordo com os dados obtidos, conclui-se que rações economicamente mais baratas são menos nutritivas e que deve se ofertar rações diferentes que supram a necessidade nutricional em cada estágio de vida dos animais e em casos de necessidades especiais o cuidado deve ser redobrado no momento de adquirir uma ração.

\section{REFERÊNCIAS}

1. Costa Júnior SH, Souza DWB, Souza MCC, Correia KM, Almeida LPS, Sousa LHV, et al. Manejo nutricional de cães e gatos domiciliados em São Luís - Maranhão. Pubvet. 2021;15(2):1-5. doi: https://doi.org/10.31533/pubvet.v15n02a741.1-5.

2. Moura WG. A construção social do mercado pet food no Brasil: estudo de caso da família Sens [trabalho de conclusão de curso] [Internet]. Florianópolis: Universidade Federal de Santa Catarina; 2013 [citado 17 Jun 2021]. Disponível em: https://repositorio.ufsc.br/bitstream/handle/123456789/114855/TCC_Wand.final.banca_1 1.07.2013_formatada $\% 20 \mathrm{~A} 5$ _pronto.pdf?sequence $=1 \&$ isAllowed $=\mathrm{y}$

3. Associação Brasileira Da Indústria De Produtos Para Animais De Estimação. Indústria pet: alta de 30\% em custos de produção afetam crescimento em 2020 [Internet]. São Paulo: ABINPET; 2019 [citado 17 Jun 2021]. Disponível em: http://abinpet.org.br/industria-pet-alta-de-30-em-custos-de-producao-afetam-crescimentoem-

2020/\#: :text=balan\%c3\%a7o\%202019\%20\%7co\%20faturamento $\% 20$ da,foi $\% 20 \mathrm{de} \% 205$ $\% 2 \mathrm{c} 3 \% 25$

4. Casa Prática Qualitá. Ração? Saiba como sempre oferecer uma boa alimentação para o seu pet, 2020 [Internet]. São Paulo: Casa Prática Qualitá; 2019 [citado 17 Jun 2021]. Disponível em: https://www.casapraticaqualita.com.br/noticia/quais-as-diferencas-entreos-tipos-de-racao-saiba-como-sempre-oferecer-uma-boa-alimentacao-para-o-seupet_a1057/1

5. Alinutri Nutrição Animal. Entenda a diferença entre rações Standard, Premium e Super Premium [Internet]. Espírito Santo: Alinutri Nutrição Animal; 2018 [citado 17 Ago 2021]. Disponível em: https://nutriave.com.br/blog/entenda-a-diferenca-entre-racoes-standardpremium-e-super-premium/ 
6. QuestionPro. Valor do produto x preço: como definir e traçar estratégias? [Internet]. QuestionPro Survey Software; 2021 [citado 17 Ago 2021]. Disponível em: https://www.questionpro.com/blog/pt-br/valor-do-produto-versus-preco-como-definir-emelhorar/

7. Brasil. Instrução Normativa $n^{\circ} 9$, de 9 de Julho de 2003. Aprova regulamento técnico sobre fixação de padrões de identidade qualidade de alimentos completos e de alimentos especiais destinados a cães e gatos. Diário Oficial da União. 14 Jul 2003.

8. Brasil. Ministério da Agricultura, Pecuária e Abastecimento. Instrução normativa $\mathrm{n}^{\mathrm{o}} 30$, de 5 de Agosto de 2009 [Internet]. Brasília: MAPA; 2009 [citado 17 Ago 2021]. Disponível em: http://sistemasweb.agricultura.gov.br/sislegis/action/detalhaAto.do?method=visualizarAt oPortalMapa\&chave $=1312271284$

9. Welti-chanes J, Vergara BF. Actividad de agua. Concepto y aplicación en alimentos con alto contenido de humedad. In: Aguilera JM. Temas en tecnología de alimentos. Cidade do México: Instituto Politécnico Nacional; 1997. Cap. 1, p. 11-43.

10. Souza VT. Composição nutricional e avaliação de rótulos de rações secas para cães e gatos adultos comercializadas em Rio Branco-AC. Braz J Dev [Internet]. 2020 [citado 20 Ago 2021];6(6):40792-803. Disponível em: https://www.brazilianjournals.com/index.php/BRJD/article/view/12211/10253

11. Carciofi AC. Fontes de proteína e carboidratos para cães e gatos. Rev Bras Zootec [Internet]. 2008 [citado 20 Ago 2021];37 Supl esp:28-41. Disponível em: https://www.scielo.br/j/rbz/a/gnxFLVHLWWGVPdYncVtHwLt/abstract/?lang=pt

12. Huber TNL, Wilson RC, McGarity SA. Variations in digestibility of dry dog foods with identical label guaranteed analysis. J Am Anim Hosp Assoc. 1986;22(5):571-5.

13. Sabchuk TT, Lowndes FG, Scheraiber M, Silva LP, Felix AP, Maiorka A, et al. Effect of soya hulls on diet digestibility, palatability, and intestinal gas production in dogs. Anim Feed Sci Technol. 2017;225:134-42. doi: https://doi.org/10.1016/j.anifeedsci.2017.01.011.

14. Sunvold GD, Fahey Junior GC, Merchen NR, Bourquin LD, Titgemeyer EC, Bauer LL, et al. Dietary fiber for cats: in vitro fermentation of selected fiber sources by cat fecal inoculum and in vivo utilization of diets containing selected fiber sources and their blends. J Anim Sci. 1995;73(8):2329-39. doi: https://doi.org/10.2527/1995.7382329x.

15. Carciofi AC, Vasconcellos RS, Borges NC, Moro JV, Prada F, Fraga VO. Composição nutricional e avaliação de rótulo de rações secas para cães comercializadas em Jaboticabal-SP. Arq Bras Med Vet. 2006;58(3):421-6. doi: https://doi.org/10.1590/S0102-09352006000300021.

16. Earle KE, Kienzle E, Opitz B, Smith PM, Maskell IE. Fiber affects digestibility of organic matter and energy in pet foods. J Nutr [Internet]. 1998 [citado 22 Ago 2021];128(12):2798-800. Disponível em: https://academic.oup.com/jn/article/128/12/2798S/4724305 
17. Afonso MVR, Jesus NG, Oliveira NS, Rabelo WO, Jorge ALTA, Almeida GM. Avaliação e composição nutricional de rações secas para cães. Pubvet. 2021;15(7):1-7. doi: https://doi.org/10.31533/pubvet.v15n07a853.1-7.

18. Carciofi AC, Teshima E, Bazolli RS, Brunetto MA, Vasconcellos RS, Oliveira LD, et al. Qualidade e digestibilidade de alimentos comerciais de diferentes segmentos de mercado para cães adultos. Rev Bras Saude Prod Anim [Internet]. 2009 [citado 23 Ago 2021);10(2):489-500. Disponível em: https://periodicos.ufba.br/index.php/rbspa/article/view/40305/22441

19. Seixas JRC, Araujo WA, Filtrin CA, Mucio CR. Fontes proteicas para alimentos pet. In: Anais do 3o Simpósio sobre Nutrição de Animais de Estimação; 2003; Campinas (SP). Campinas: Colégio Brasileiro de Nutrição Animal Campinas; 2003. p. 97-116.

20. Panasevich MR, Kerr KR, Serao MCR, Godoy MRC, Guérin-Deremaux L, Lynch GL, et al. Evaluation of soluble corn fiber on chemical composition and nitrogen-corrected true metabolizable energy and its effects on in vitro fermentation and in vivo responses in dogs. J Anim Sci. 2015;93(5):2191-200. doi: https://doi.org/10.2527/jas.2014-8425.

21. Wortinger A. Nutrição para cães e gatos. São Paulo: Roca; 2009.

22. Association of American Feed Control Officials. Publications 2004 [Internet]. Oxford: AAFCO; 2004 [citado 25 Ago 2021]. Disponível em: https://www.aafco.org/Publications

23. Vellasco CR, Gomes PC, Donzele JL, Rostagno HS, Calderano AA, Mello HHC, et al. Níveis de cálcio e relação cálcio: fósforo em rações para poedeiras leves de 24 a 40 Semanas de Idade. Cienc Anim Bras. 2016;17(2):206-16. doi: https://doi.org/10.1590/1089-6891v17i226916

24. Nelson RW, Couto CG. Medicina interna de pequenos animais. 4a ed. Rio de Janeiro: Elsevier; 2010. Desequilíbrio eletrolítico; p. 880-1.

25. Oliveira DE. Minerais: funções, deficiências, toxidez e outros aspectos da suplementação [Internet]. São Paulo: Agroceres Nutrição Animal Ltda; 2001 [citado 20 Nov 2014]. Disponível em: http://www.agroceresnutricao.com.br/artigos/apostilatecnicaminerais

26. Chamone CMK. Principais deficiências nutricionais em gatos: revisão de literatura [trabalho de conclusão de curso] [Internet]. São Paulo: Centro de Estudos Superiores de Maceió, Fundação Educacional Jayme de Altavila; 2013 [citado 26 Ago 2021]. Disponível em: https:/www.passeidireto.com/arquivo/88495982/principais-deficienciasnutricionais-em-gatos

27. Rogers QR, Morris JG. Do cats really need more protein? J Small Anim Pract. 1982;21(9):521-32. doi: https://doi.org/10.1111/j.1748-5827.1982.tb02513.x.

28. National Research Council. Nutrient requirements of dogs and cats. Washington: The National Academies Press; 2006.

29. Reis C. Abordagem clínica e nutricional do paciente renal felino [trabalho de conclusão de curso] [Internet]. Porto Alegre: Faculdade de Medicina Veterinária, Universidade

Lima AJS, Boechat YL, Genovez LMC, Cabral CF, Silva LBR. Análise de informações nutricionais em rações para gatos. Vet. e Zootec. 2021 dez.; v28: 001-015. 
Federal do Rio Grande do Sul; 2017 [citado 27 Ago 2021]. Disponível em: http://www.lume.ufrgs.br/handle/10183/148190

30. Birchard SJ, Sherding RG. Manual Saunders: clínica de pequenos animais. 3a ed. São Paulo: Roca; 2008.

31. Silva LPS, Nora Júnior RCH, Pereira CMC, Bernardino VMP. Manejo nutricional para cães e gatos obesos. Pubvet. 2019;13(5):1-12. doi: https://doi.org/10.31533/pubvet.v13n5a339.1-12.

32. Case LP, Daristotle L, Hayek MG, Raasch MF. Canine and feline nutrition: a resource for companion animal professionals. 3th ed. Maryland Heights: Mosby Elsevier; 2010.

33. Mendes FF, Rodrigues DF, Prado YCL, Araújo EG. Obesidade felina. Enciclopedia Biosfera [Internet]. 2013 [citado 27 Ago 2021];9(16):1602-25. Disponível em: https://www.conhecer.org.br/enciclop/2013a/agrarias/Obesidade\%20Felina.pdf

34. Farcas AK, Larsen JA, Owens TJ, Nelson RW, Kass PH, Fascetti AJ. Evaluation of total dietary fiber concentration and composition of commercial diets used for management of diabetes mellitus, obesity, and dietary fat-responsive disease in dogs. J Am Vet Med Assoc. 2015;247(5):501-7. doi: https://doi.org/10.2460/javma.247.5.501.

35. Melo MG, Duarte JS, Mizuguti P, Honorio G, Martins FP, Honorato CA. Composição bromatológica e qualidade nutricional das rações secas para cães. J Agric Sci [Internet]. 2014 [citado 27 Ago 2021];1(1):149-60. Disponível em: https://www2.ufrb.edu.br/apa/component/phocadownload/category/14-ano-14vol1?download=166: composicao-bromatologica-e-qualidade-nutricional-das-racoessecas-para-caes

36. Santos PA. Composição nutricional e avaliação do rótulo de rações secas para cães adultos comercializadas em Recife - PE. In: Anais da 10a Jornada de Ensino, Pesquisa e Extensão-JEPEX; 2010; Recife. Recife: Universidade Federal Rural de Pernambuco; 2010.

Recebido em: 13/09/2021 Aceito em: 16/12/2021 